\title{
Voltage Gain Derivation Based on Energy-Balanced Criterion for a Novel Hybrid-Input PV-Wind Power Conversion System
}

\author{
Chih-Lung Shen, Tsair-Chun Liang, Siou-Hong Zhou, and Su-Wen Wang \\ Department of Electronic Engineering, National Kaohsiung First University of Science and Technology, Kaohsiung 82445, Taiwan \\ Correspondence should be addressed to Chih-Lung Shen; clshen@ccms.nkfust.edu.tw
}

Received 12 October 2014; Accepted 7 December 2014

Academic Editor: Mo Li

Copyright ( $) 2015$ Chih-Lung Shen et al. This is an open access article distributed under the Creative Commons Attribution License, which permits unrestricted use, distribution, and reproduction in any medium, provided the original work is properly cited.

\begin{abstract}
This paper applies energy-balanced criterion to a novel hybrid-input PV-wind power conversion system (HPWPCS) for voltage gain derivation. With the energy-balanced concept, complicated mathematical problems related to voltage gain derivation can be readily resolved. Based on the derived results, it is proven that the proposed HPWPCS is able to process two different kinds of renewable energy resources simultaneously. Even though the HPWPCS includes seven capacitors and three magnetic components, its voltage gain still can be found by the mathematical analysis. In the theoretical derivation, only the energy status of output inductor is dealt with such that complicated derivation procedure is avoided. This analysis method can also be applied to other hybrid green-energy conversion systems. In this paper, a $200 \mathrm{~W} 50 \mathrm{kHz}$ prototype of HPWPCS is built and examined to verify the mathematical results.
\end{abstract}

\section{Introduction}

With rapid development of industry and commerce, requirement for electricity has been growing dramatically. Conventionally, electric power is mainly generated from fossil fuels. However, this kind of energy resources is highly limited and will exhaust in the near future. Furthermore, the environmental pollution caused from overuse of fossil energy has destroyed ecological balance, and a large amount of carbon dioxide yielded from combustion of fossil fuels has also resulted in greenhouse effects seriously. Therefore, adopting renewable and clean energy resources to replace fossil fuels for electric power generation is a research of great urgency [1-5].

At present, various renewable energy resources, such as hydraulic energy, wind energy, tidal energy, and solar energy, are feasible for power generation. Among them, solar energy and wind energy attract more interests owing to the noiseless, pollution-free, nonradioactive, and inexhaustible characteristics. Solar energy is converted into electric power by photovoltaic (PV) arrays, while wind energy is converted into electric power by wind turbine. In PV or wind generation system, converters have to be adopted to accomplish power processing [6-12]. Traditionally, the structure containing two separate converters is commonly used to accomplish power conversion. Since PV arrays and wind turbine are complementary power sources, development of single converter, instead of two individual converters, simultaneously to cope with the hybrid inputs of PV and wind power is current trend [13-16]. However, finding voltage gain for a single-structure converter is a complex mathematical problem.

In this paper, a novel hybrid-input PV-wind power converter is proposed first, and then energy-balanced criterion is applied to derive the voltage gain of the converter. The proposed HPWPCS has the intrinsic characteristics of galvanic isolation, extra high voltage gain, and individual power control. The HPWPCS comprises two active switches, ten diodes, seven capacitors, two coupled inductors, and one output inductor. While applying energy-balanced criterion to the output inductor, the voltage gain can readily be found without complex calculation. This paper will detail the corresponding derivation procedure. To prove that the theoretically derived voltage gain can be consistent with practical system, a prototype of HPWPCS is designed, built, and measured. Hardware measurements have verified the correctness of the derivation and the validity of the proposed HPWPCS. 


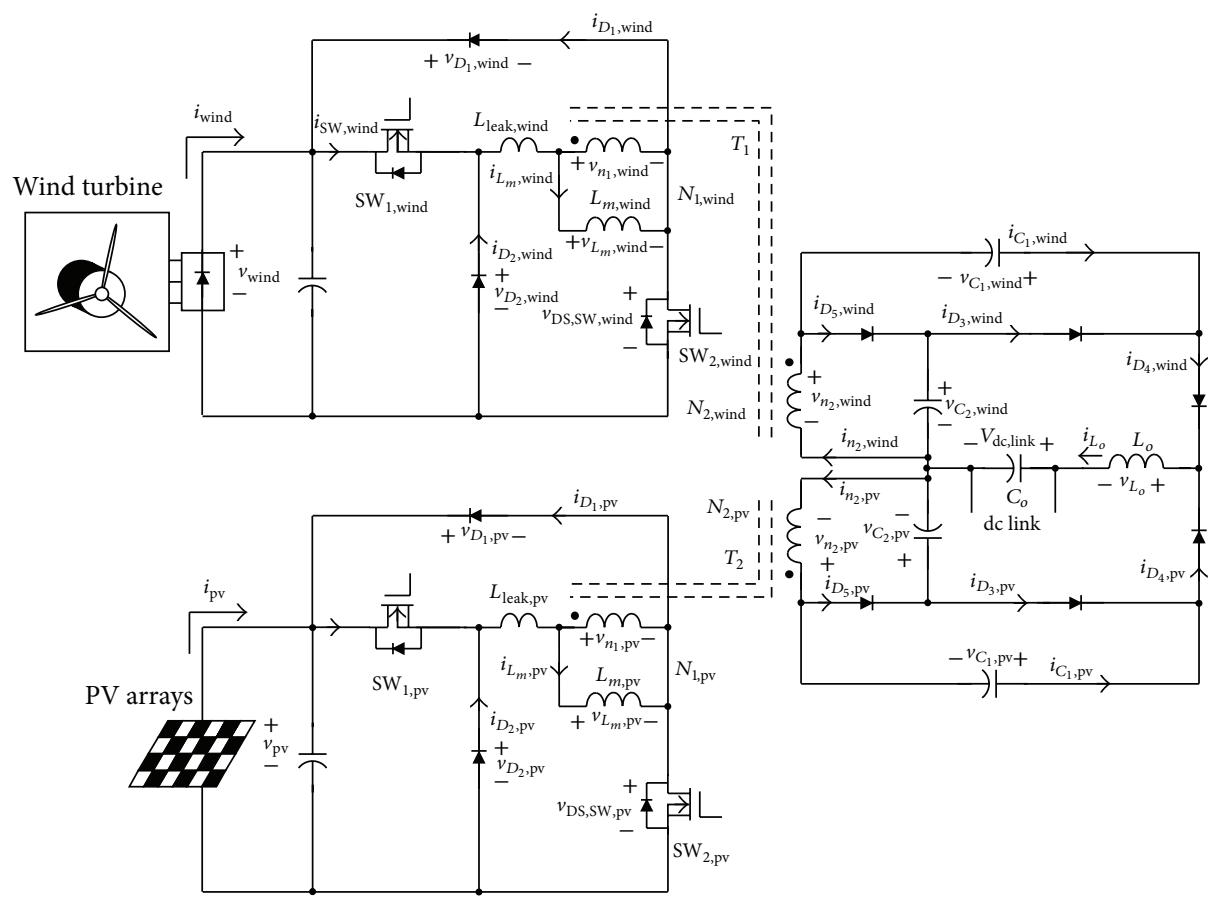

FIgURE 1: The power circuit of the proposed HPWPCS.

\section{Power Stage Configuration}

The proposed HPWPCS not only can process PV power but also deals with wind energy. Figure 1 shows its power stage configuration, which immerges two double-ended forward converters into a single stage to possess two input ports and one output port. In Figure 1, active switches can operate individually so as to convert two different kinds of renewable energy sources. The coupled inductors, $T_{1}$ and $T_{2}$, galvanically isolate the primary side from the secondary one and can step up/down input voltage. In addition, both coupled inductors can fulfill forward and flyback behaviors to process input energy to achieve voltage stacking for high voltage output. The energy stored in the two leakage inductances of the coupled inductors, $L_{\text {leak,wind }}$ and $L_{\text {leak,pv }}$, can be recycled totally, which, as a result, can improve conversion efficiency significantly. The HPWPCS can draw the upmost power from PV arrays and wind turbine by means of controlling active switches and fulfilling maximum power point tracking (MPPT). The control of HPWPCS is implemented on the chip of dsPIC30F4011 to lower discrete components and cost.

\section{Operation Analysis}

Before the operation analysis, some assumptions are made as follows. (1) All diodes are ideal. (2) The output inductor $L_{o}$ and magnetizing inductances, $L_{m \text {,wind }}$ and $L_{m, \mathrm{pv}}$, are in continuous conduction mode (CCM). (3) The internal resistance and parasitic capacitance in active switch are neglected. (4) Both leakage inductances $L_{\text {leak,wind }}$ and $L_{\text {leak,pv }}$ are much less than $L_{m \text {,wind }}$ and $L_{m, \mathrm{pv}}$. Based on the above assumptions, the operation of HPWPCS contains six stages over one switching cycle. The six corresponding equivalents and related conceptual key waveforms are presented in Figures 2 and 3, respectively. The followings will detail its operation principle stage by stage.

(1) Stage 1 (Figure $\left.2(\mathrm{a}), t_{0}-t_{1}\right)$ : during this time interval, the power switches $\mathrm{SW}_{1 \text {,wind }}$ and $\mathrm{SW}_{2, \text { wind }}$ are turned on simultaneously but $S W_{1, p v}$ and $S W_{2, p v}$ are in off state. The leakage inductance $L_{\text {leak,wind }}$ and magnetizing inductance $L_{m \text {,wind }}$ are charging and so does the output inductor $L_{o}$. The current flowing through $N_{1 \text {,wind }}$ will be transferred to the secondary winding $N_{2 \text {,wind }}$, to charge the capacitors $C_{2 \text {,wind }}$ and $C_{o}$. Meanwhile, the inductor $L_{m, \mathrm{pv}}$ dumps energy to secondary winding via transformer $T_{2}$. The energy in $L_{m, \mathrm{pv}}$ and $C_{2, \mathrm{pv}}$ charges $C_{1, \mathrm{pv}}$. This stage is ended as soon as the switches $\mathrm{SW}_{1 \text {,wind }}$ and $\mathrm{SW}_{2 \text {,wind }}$ are turned off.

(2) Stage 2 (Figure 2(b), $t_{1}-t_{2}$ ): at the moment that the switches $\mathrm{SW}_{1 \text {,wind }}$ and $\mathrm{SW}_{2 \text {,wind }}$ are turned off, the operation of HPWPCS enters into Stage 2. The energy stored in leakage inductance $L_{\text {leak,wind }}$ is recycled to the input and transferred to the secondary winding via the path of $N_{1 \text {,wind }}, D_{1 \text {,wind }}$, and $D_{2 \text {,wind }}$. This mode ends when the current of leakage inductance $L_{\text {leak,wind }}$ dumps to zero.

(3) Stage 3 (Figure 2(c), $t_{2}-t_{3}$ ): during this stage, all the active switches $\mathrm{SW}_{1 \text {,wind }}, \mathrm{SW}_{2 \text {,wind }}, \mathrm{SW}_{1, \mathrm{pv}}$, and $\mathrm{SW}_{2, \mathrm{pv}}$ are kept in off state. The magnetizing inductance $L_{m \text {,wind }}$ dumps energy to secondary winding to charge the capacitor $C_{1 \text {,wind }}$ via $N_{2 \text {,wind }}, C_{2 \text {,wind }}$, and $D_{3 \text {,wind }}$. Meanwhile, the inductance $L_{m, \mathrm{pv}}$ also dumps energy 


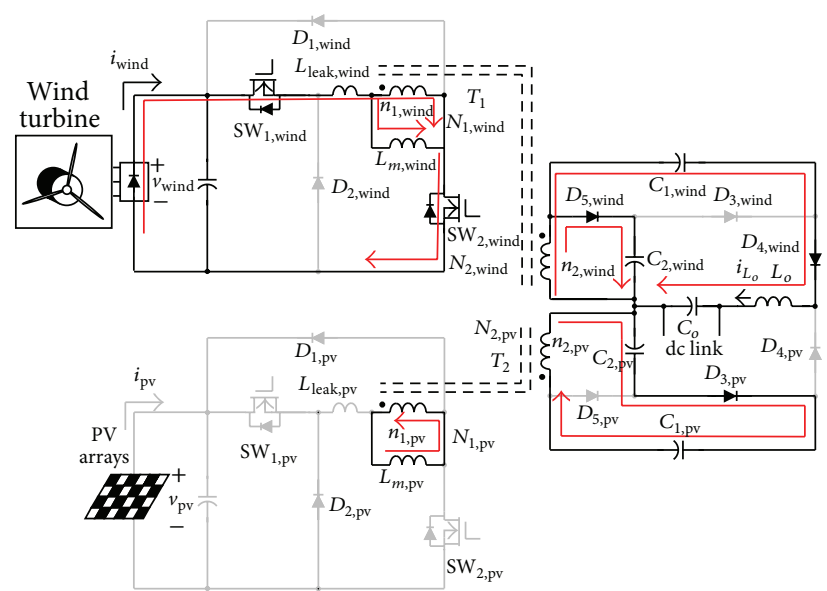

(a)

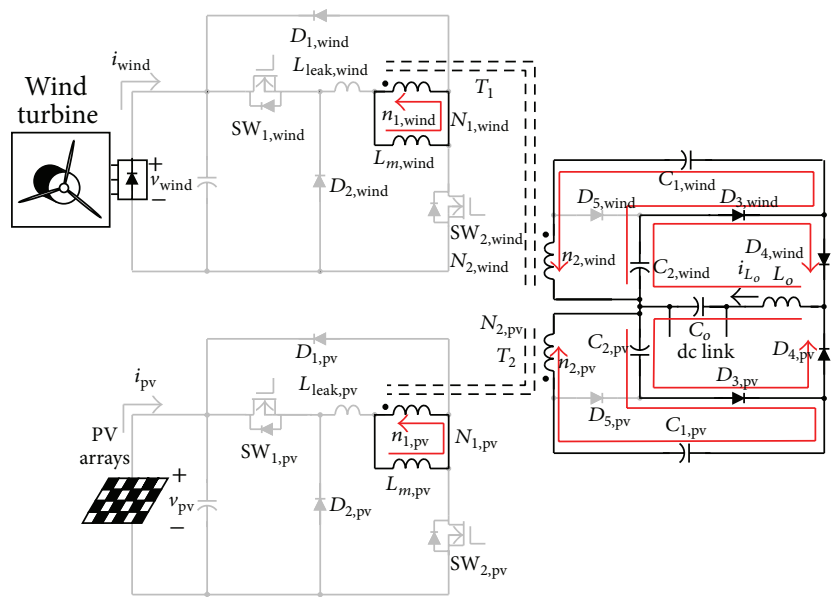

(c)

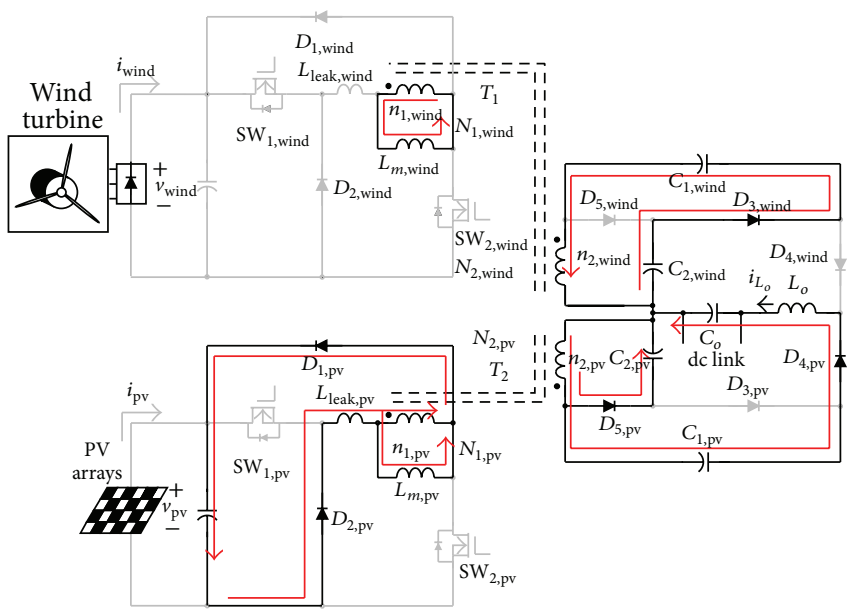

(e)

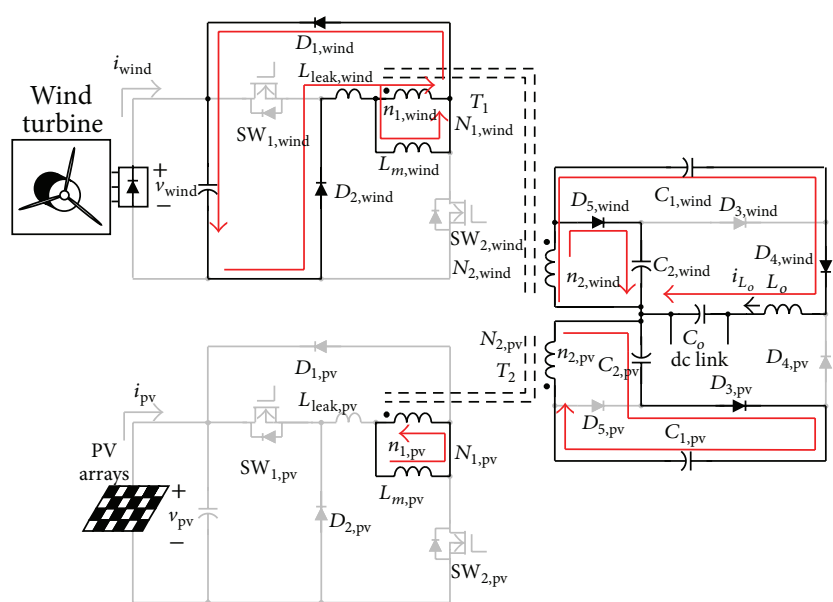

(b)

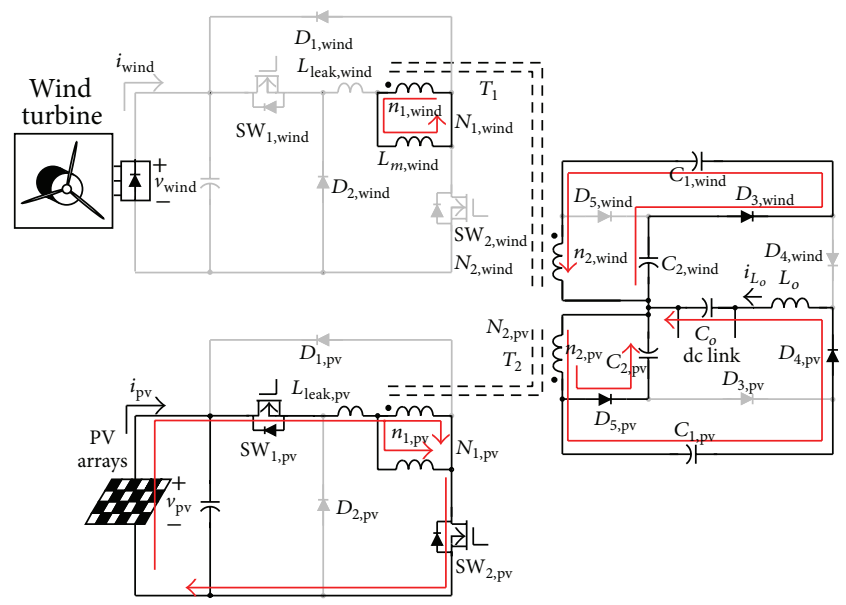

(d)

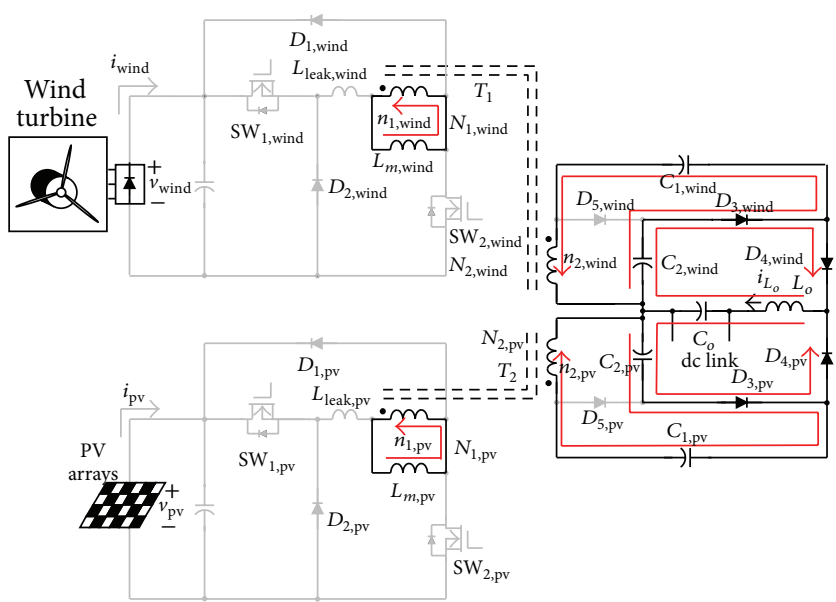

(f)

Figure 2: Equivalent circuits of the proposed HPWPCS: (a) Stage 1, (b) Stage 2, (c) Stage 3, (d) Stage 4, (e) Stage 5, and (f) Stage 6. 


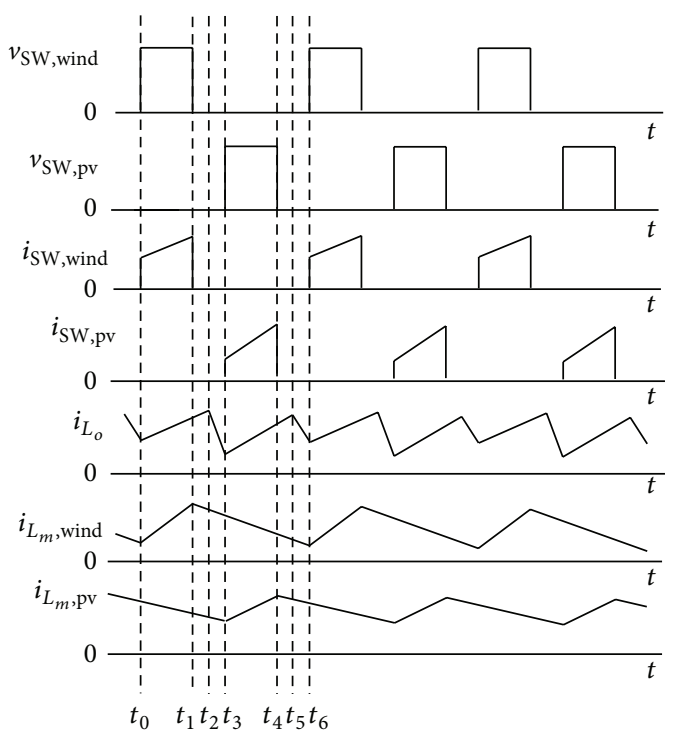

FIgURE 3: Conceptual waveforms to depict the operation of the proposed HPWPCS.

to $C_{1, \mathrm{pv}}$ via $N_{2, \mathrm{pv}}, C_{2, \mathrm{pv}}$, and $D_{3, \mathrm{pv}}$. The output inductor $L_{o}$ releases energy to the dc link for load powering. As $\mathrm{SW}_{1, \mathrm{pv}}$ and $\mathrm{SW}_{2, \mathrm{pv}}$ are turned on, the next stage begins.

(4) Stage 4 (Figure $2(\mathrm{~d}), t_{3}-t_{4}$ ): the power switches $S W_{1, p v}$ and $\mathrm{SW}_{2, \mathrm{pv}}$ are on but $\mathrm{SW}_{1 \text {,wind }}$ and $\mathrm{SW}_{2 \text {,wind }}$ are off. The HPWPCS will forward PV power to the output. The magnetizing inductance $L_{m, \mathrm{pv}}$ starts charging during this interval, and the current through $N_{1, \mathrm{pv}}$ is transferred to the secondary winding of $T_{2}$ to charge the capacitor $C_{2, \mathrm{pv}}$. With respect to the processing of wind energy, the HPWPCS sustains the same circuit behavior as in Stage 3.

(5) Stage 5 (Figure 2(e), $t_{4}-t_{5}$ ): as the switches $\mathrm{SW}_{1, \mathrm{pv}}$ and $\mathrm{SW}_{2, \mathrm{pv}}$ are turned off, Stage 5 begins and the energy stored in leakage inductance $L_{\text {leak,pv }}$ will be recycled to the input by the path of $L_{\text {leak,pv }}-N_{1, \mathrm{pv}}-D_{1, \mathrm{pv}}-D_{2, \mathrm{pv}}$. The current of $L_{\text {leak,pv }}$ decreases linearly. While this current drops to zero, circuit operation enters into next stage.

(6) Stage 6 (Figure 2(f), $t_{5}-t_{6}$ ): in this mode, all active switches are open and the operation is the same as that in Stage 3. The magnetizing inductance $L_{m \text {,wind }}$ releases energy to the secondary of $T_{1}$ and so does the $L_{m, \mathrm{pv}}$ to the secondary of $T_{2}$. When $\mathrm{SW}_{1 \text {,wind }}$ and $\mathrm{SW}_{2 \text {,wind }}$ are closed again, the operation of HPWPCS returns to Stage 1.

\section{Voltage Gain Derivation}

Suppose that all capacitances are large enough to sustain capacitor voltages at constants and the leakage inductances of $T_{1}$ and $T_{2}$ are much smaller than magnetizing inductances. As shown in Figure 4, the switching period of the HPWPCS is $T_{s}$. During the time interval $T_{s}$, switches $\mathrm{SW}_{1 \text {,wind }}$ and $\mathrm{SW}_{2 \text {,wind }}$

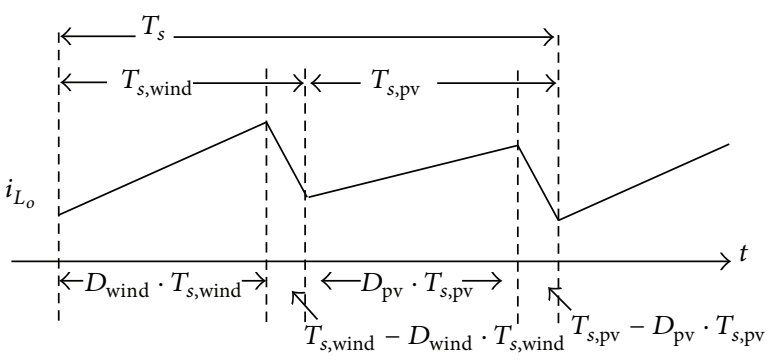

FIGURE 4: Illustration of the current waveform of output inductor and related time intervals.

are closed for $D_{\text {wind }} T_{s \text {, wind }}$ and open for $\left(1-D_{\text {wind }}\right) T_{s \text {, wind }}$ while switches $\mathrm{SW}_{1, \mathrm{pv}}$ and $\mathrm{SW} \mathrm{W}_{2, \mathrm{pv}}$ are closed for $D_{\mathrm{pv}} T_{s, \mathrm{pv}}$ and open for $\left(1-D_{\mathrm{pv}}\right) T_{s, \mathrm{pv}}$. The $T_{s \text {, wind }}$ stands for the interval that the HPWPCS deals with wind turbine energy, while $T_{s, \mathrm{pv}}$ stands for PV panel. That is,

$$
T_{s, \text { wind }}+T_{s, \mathrm{pv}}=T_{s}
$$

According to the operation principle described in Stages 1, 3, 4 , and 6 , the output inductor current $i_{L_{o}}$ will increase linearly while absorbing energy and decrease linearly while releasing energy. The waveform of output inductor current is illustrated in Figure 4.

Since HPWPCS adopts two coupled inductors, the coupling coefficient $k$ will be a key parameter in the derivation. The $k$ can be found by the following relationship:

$$
k=\sqrt{1-\frac{L_{\mathrm{sc}}}{L_{\text {open }}}},
$$

where $L_{\mathrm{sc}}$ is the measured inductance from the primary while the secondary is short circuit and $L_{\text {open }}$ represents the measured primary-side inductance while the secondary is open circuit. With respect to $T_{1}$, when the switches $S W_{1 \text {,wind }}$ and $\mathrm{SW}_{2 \text {,wind }}$ are closed, the voltage across $N_{1}$ is

$$
v_{n_{1}, \text { wind }}=v_{\text {wind }} \cdot k_{\text {wind }}^{2} \text {, }
$$

in which $k_{\text {wind }}$ expresses the coupled coefficient of $T_{1}$. Thus, at this switch-on status the voltage $v_{n_{2} \text {,wind }}$ is calculated by

$$
v_{n_{2} \text {, wind }}=v_{n_{1} \text {, wind }} \cdot \frac{N_{2, \text { wind }}}{N_{1, \text { wind }}} \text {. }
$$

Substituting (3) into (4) yields

$$
v_{n_{2} \text {,wind }}=v_{\text {wind }} \cdot k_{\text {wind }}^{2} \cdot \frac{N_{2, \text { wind }}}{N_{1, \text { wind }}} .
$$

From the equivalent of Stage 2 (switches $\mathrm{SW}_{1 \text {,wind }}$ and $\mathrm{SW}_{2 \text {,wind }}$ are off), it can be found that the voltage of the capacitor $C_{2 \text {,wind }}, v_{C_{2} \text {,wind }}$, is equal to the voltage of the secondary of $T_{1}$. That is,

$$
v_{C_{2} \text {,wind }}=v_{n_{2} \text {,wind }} \text {. }
$$


Therefore, the following equation holds:

$$
v_{C_{2} \text {,wind }}=v_{\text {wind }} \cdot k_{\text {wind }}^{2} \cdot \frac{N_{2, \text { wind }}}{N_{1, \text { wind }}} .
$$

From Figure 2(c), the voltage across the capacitor $C_{1 \text {,wind }}$ can be determined by

$$
v_{C_{1}, \text { wind }}=v_{C_{2} \text {,wind }}+v_{n_{2}, \text { wind }} .
$$

From (7), the above equation can be rewritten as

$$
\begin{aligned}
v_{C_{1} \text {,wind }}= & v_{\text {wind }} \cdot k_{\text {wind }}^{2} \cdot \frac{N_{2, \text { wind }}}{N_{1, \text { wind }}} \\
& +v_{\text {wind }} \cdot k_{\text {wind }}^{2} \cdot \frac{N_{2, \text { wind }}}{N_{1, \text { wind }}} \cdot \frac{D_{\text {wind }}}{1-D_{\text {wind }}} .
\end{aligned}
$$

Rearranging (9) gives

$$
v_{C_{1} \text {,wind }}=\frac{k_{\text {wind }}^{2}}{1-D_{\text {wind }}} \cdot \frac{N_{2, \text { wind }}}{N_{1, \text { wind }}} \cdot v_{\text {wind }} .
$$

While $\mathrm{SW}_{1 \text {,wind }}$ and $\mathrm{SW}_{2 \text {,wind }}$ are closed, referring to Figure 2(a) and applying Kirchhoff's voltage law (KVL) to the loop of $N_{2 \text {,wind }}-C_{1 \text {,wind }}-D_{4 \text {,wind }}-L_{o}-C_{o}$, the output inductor voltage $v_{L_{o}}$ can be obtained:

$$
v_{L_{o}}=L_{o} \frac{d i_{L_{o}}}{d t}=v_{n_{2} \text {,wind }}+v_{C_{1} \text {, wind }}-V_{\mathrm{dc}, \text { link }} .
$$

Substituting (5) and (10) into (11) results in

$$
\begin{aligned}
v_{L_{o}}= & \frac{v_{\text {wind }} \cdot k_{\text {wind }}^{2} \cdot N_{2, \text { wind }}}{N_{1, \text { wind }}} \\
& +\frac{k_{\text {wind }}^{2} \cdot v_{\text {wind }} \cdot N_{2, \text { wind }}}{\left(1-D_{\text {wind }}\right) \cdot N_{1, \text { wind }}}-V_{\text {dc,link }} .
\end{aligned}
$$

Regarding the expression for $v_{L}$ during the period of both switches $S W_{1 \text {,wind }}$ and $S W_{2 \text {,wind }}$ being open, we can apply KVL to the loop of $C_{2 \text {,wind }}-D_{3 \text {,wind }}-D_{4 \text {,wind }}-L_{o}-C_{o}$ as shown in Figure 2(c) and then obtain

$$
v_{L_{o}}=\left(v_{\text {wind }} \cdot k_{\text {wind }}^{2} \cdot \frac{N_{2, \text { wind }}}{N_{1, \text { wind }}}\right)-V_{\text {dc,link }} .
$$

While considering the expression of $v_{L_{o}}$ during the period of $T_{s, \mathrm{pv}}$, Figures 2(d) and 2(f) will be contacted and the similar derivation procedure as above is adopted. During the period of $D_{\mathrm{pv}} T_{s, \mathrm{pv}}$, referring to Figure 2(d), the $v_{n_{1}, \mathrm{pv}}$ and $v_{n_{2}, \mathrm{pv}}$ can be found as follows:

$$
\begin{aligned}
& v_{n_{1}, \mathrm{pv}}=v_{\mathrm{pv}} \cdot k_{\mathrm{pv}}^{2}, \\
& v_{n_{2}, \mathrm{pv}}=v_{n_{1}, \mathrm{pv}} \cdot \frac{N_{2, \mathrm{pv}}}{N_{1, \mathrm{pv}}}=v_{\mathrm{pv}} \cdot k_{\mathrm{pv}}^{2} \cdot \frac{N_{2, \mathrm{pv}}}{N_{1, \mathrm{pv}}},
\end{aligned}
$$

where the $k_{\mathrm{pv}}$ is the coupling coefficient of $T_{2}$. The voltage across $C_{2}, v_{C_{2}, \mathrm{pv}}$, is equal to $v_{n_{2}, \mathrm{pv}}$. That is,

$$
v_{C_{2}, \mathrm{pv}}=v_{\mathrm{pv}} \cdot k_{\mathrm{pv}}^{2} \cdot \frac{N_{2, \mathrm{pv}}}{N_{1, \mathrm{pv}}} .
$$

From Figure 2(f), the $v_{C_{1}, \mathrm{pv}}$ is the sum of $v_{C_{2}, \mathrm{pv}}$ and $v_{n_{2}, \mathrm{pv}}$. As a result, the $v_{C_{1}, \mathrm{pv}}$ can be described as

$$
v_{C_{1}, \mathrm{pv}}=\frac{k_{\mathrm{pv}}^{2}}{1-D_{\mathrm{pv}}} \cdot \frac{N_{2, \mathrm{pv}}}{N_{1, \mathrm{pv}}} \cdot v_{\mathrm{pv}}
$$

While $S W_{1, p v}$ and $S W_{2, p v}$ are closed, as shown in Figure 2(d), from the loop enclosed by $N_{2, \mathrm{pv}}, C_{1, \mathrm{pv}}, D_{4, \mathrm{pv}}, L_{o}$, and $C_{o}$, one can find $v_{L_{o}}$ by the use of KVL:

$$
v_{L_{o}}=v_{n_{2}, \mathrm{pv}}+v_{C_{1}, \mathrm{pv}}-V_{\mathrm{dc}, \text { link }} .
$$

The $v_{n_{2}, \mathrm{pv}}$ and $v_{\mathrm{C}_{1}, \mathrm{pv}}$ are substituted for (15) and (17), respectively, which yields

$$
v_{L_{o}}=\frac{v_{\mathrm{pv}} \cdot k_{\mathrm{pv}}^{2} \cdot N_{2, \mathrm{pv}}}{N_{1, \mathrm{pv}}}+\frac{k_{\mathrm{pv}}^{2} \cdot v_{\mathrm{pv}} \cdot N_{2, \mathrm{pv}}}{\left(1-D_{\mathrm{pv}}\right) \cdot N_{1, \mathrm{pv}}}-V_{\mathrm{dc}, \text { link }}
$$

In regard to the expression for output inductor voltage while $\mathrm{SW}_{1, \mathrm{pv}}$ and $\mathrm{SW}_{2, \mathrm{pv}}$ are off, from the loop of $C_{2, \mathrm{pv}}-D_{3, \mathrm{pv}}-D_{4, \mathrm{pv}}-L_{o}-C_{o}$ shown in Figure 2(f), one can find

$$
v_{L_{o}}=\left(v_{\mathrm{pv}} \cdot k_{\mathrm{pv}}^{2} \cdot \frac{N_{2, \mathrm{pv}}}{N_{1, \mathrm{pv}}}\right)-V_{\mathrm{dc}, \text { link }}
$$

The output inductor charges energy during the two time intervals, $D_{\text {wind }} T_{s \text {,wind }}$ and $D_{\mathrm{pv}} T_{s, \mathrm{pv}}$. On the contrary, during $\left(1-D_{\text {wind }}\right) T_{s \text {,wind }}$ and $\left(1-D_{\mathrm{pv}}\right) T_{s, \mathrm{pv}}$, the output inductor discharges. In steady state operation and over one switching cycle, the stored energy and released energy in output inductor are identical. Thus, from (12), (13), (19), and (20), one can derive the following relationship:

$$
\begin{aligned}
& \left(\left(v_{\text {wind }} \cdot \frac{N_{2, \text { wind }}}{N_{1, \text { wind }}} \cdot k_{\text {wind }}^{2}\right.\right. \\
& \left.+\frac{v_{\text {wind }} \cdot N_{2, \text { wind }} / N_{1, \text { wind }} \cdot k_{\text {wind }}^{2}}{1-D_{\text {wind }}}-V_{\text {dc,link }}\right) \\
& \left.+D_{\text {wind }} \cdot T_{s, \text { wind }}\right) \\
& +\left(\left(v_{\mathrm{pv}} \cdot \frac{N_{2, \mathrm{pv}}}{N_{1, \mathrm{pv}}} \cdot k_{\mathrm{pv}}^{2}\right.\right. \\
& \left.+\frac{v_{\mathrm{pv}} \cdot N_{2, \mathrm{pv}} / N_{1, \mathrm{pv}} \cdot k_{\mathrm{pv}}^{2}}{1-D_{\mathrm{pv}}}-V_{\mathrm{dc}, \text { link }}\right) \\
& \left.\cdot D_{\mathrm{pv}} \cdot T_{s, \mathrm{pv}}\right)
\end{aligned}
$$


TABLE 1: The specifications of the prototype.

Switching frequency of each channel $\left(f_{s}\right)$
Output voltage $\left(V_{o}\right)$
Output power $\left(P_{o}\right)$
Voltage ripple $\left(V_{o, \text { ripple }}\right)$
Rated input voltage of wind turbine $\left(v_{\text {wind }}\right)$
Rated input voltage of PV panel $\left(v_{\mathrm{pv}}\right)$
Efficiency $(\eta)$
\[ \left(\left(V_{\mathrm{dc}, \text { link }}-v_{\mathrm{wind}} \cdot \frac{N_{2, \mathrm{wind}}}{N_{1, \text { wind }}} \cdot k_{\mathrm{wind}}^{2}\right)\right. \]
$\left.\qquad\left(1-D_{\mathrm{wind}}\right) \cdot T_{s, \text { wind }}\right)$
$+\left(\left(V_{\mathrm{dc}, \mathrm{link}}-v_{\mathrm{pv}} \cdot \frac{N_{2, \mathrm{pv}}}{N_{1, \mathrm{pv}}} \cdot k_{\mathrm{pv}}^{2}\right)\right.$
$\left.\quad \cdot\left(1-D_{\mathrm{pv}}\right) \cdot T_{s, \mathrm{pv}}\right) \cdot$

Simplifying (21) results in

$$
\begin{array}{r}
V_{\mathrm{dc}, \text { link }}=\frac{1}{2}\left(\frac{N_{2, \text { wind }} / N_{1, \text { wind }} \cdot k_{\text {wind }}^{2} \cdot v_{\text {wind }}}{1-D_{\text {wind }}}\right. \\
\left.+\frac{N_{2, \mathrm{pv}} / N_{1, \mathrm{pv}} \cdot k_{\mathrm{pv}}^{2} \cdot v_{\mathrm{pv}}}{1-D_{\mathrm{pv}}}\right)
\end{array}
$$

which reveals that the voltage gain is found and the dc-link voltage can be controlled by the duty ratios of the active switches.

\section{Experimental Verification}

To demonstrate the derived voltage gain of the proposed HPWPCS, a prototype is designed, built, and measured, of which specifications are presented in Table 1. According to the given specifications, key parameters of the prototype are analyzed and then power components are chosen. Table 2 summaries the determined parameters. In the case that all active switches are interleavedly turned on with a duty ratio of 0.38 , the corresponding control signals and input currents are presented in Figure 5. Figure 6 shows the voltages across the capacitors $C_{1, \text { wind }}$ and $C_{1, \mathrm{pv}}$, which depicts that the voltages $v_{C_{1} \text {,wind }}$ and $C_{1, \mathrm{pv}}$ can be sustained at constant level. Output inductor current $i_{L}$ is illustrated in Figure 7, in which the interval of current increasing expresses energy charging and during the current decreasing interval the inductor energy releases. Figure 8 shows the input voltages of wind turbine, PV panel, and output voltage. By substituting related parameter values into (22), it can be found that the magnitude of output voltage $v_{o}$ in Figure 8 can meet the theoretical
TABLE 2: The parameters of the prototype.

\begin{tabular}{lc}
\hline Parameter & Value \\
\hline Output capacitance $\left(C_{o}\right)$ & $10 \mu \mathrm{F}$ \\
Output inductance $\left(L_{o}\right)$ & $5 \mathrm{mH}$ \\
Input capacitance $\left(C_{\mathrm{in}}\right)$ & $100 \mu \mathrm{F}$ \\
Capacitances $\left(C_{1, \text { wind }}, C_{2, \text { wind }}, C_{1, \mathrm{pv}}\right.$, and $\left.C_{2, \mathrm{pv}}\right)$ & $5 \mu \mathrm{F}$ \\
Turn ratio of coupled inductor $T_{1}$ & $1: 2$ \\
Turn ratio of coupled inductor $T_{2}$ & $1: 3$ \\
Magnetizing inductance of $T_{1}\left(L_{m, \text { wind }}\right)$ & $800 \mu \mathrm{F}$ \\
Magnetizing inductance of $T_{2}\left(L_{m, p v}\right)$ & $800 \mu \mathrm{F}$ \\
Leakage inductance of $T_{1}\left(L_{\text {leak,wind }}\right)$ & $5 \mu \mathrm{H}$ \\
Leakage inductance of $T_{2}\left(L_{\text {leak,pv }}\right)$ & $8 \mu \mathrm{H}$
\end{tabular}

Active switches $\left(\mathrm{SW}_{1, \text { wind }}, \mathrm{SW}_{2, \text { wind }}, \mathrm{SW}_{1, \mathrm{pv}}\right.$, and IRFI4227

$\mathrm{SW}_{2, \mathrm{pv}}$ )

Diodes $\left(D_{1, \text { wind }}, D_{2, \text { wind }}, D_{1, \mathrm{pv}}\right.$, and $\left.D_{2, \mathrm{pv}}\right)$

BYV42

Diodes $\left(D_{3 \text {,wind }}, D_{4 \text {,wind }}, D_{5 \text {,wind }}, D_{3, \mathrm{pv}}, D_{4, \mathrm{pv}}\right.$, and

$\left.D_{5, \mathrm{pv}}\right)$

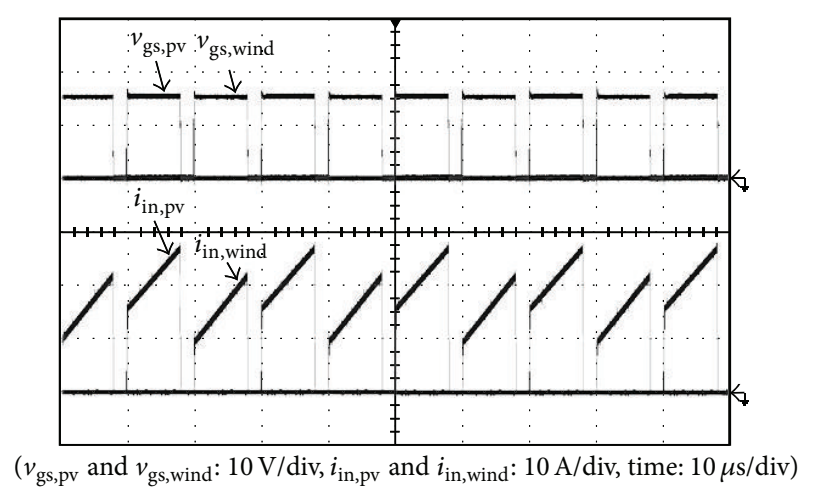

FIGURE 5: Waveforms of control signals $\left(v_{\mathrm{gs}, \mathrm{pv}}\right.$ and $\left.v_{\mathrm{gs} \text {,wind }}\right)$ and input current $\left(i_{\text {in,pv }}\right.$ and $\left.i_{\text {in,wind }}\right)$.

computing result. This has verified the correctness of the mathematical derivation in this paper. Another conclusion observed from Figure 8 is that the proposed HPWPCS still can function when PV panel is shut down from the generation system. Equation (22) can also estimate the output voltage under this situation. The measured efficiency from light load to heavy load is presented in Figure 9, in which the maximum efficiency is around $92.5 \%$.

\section{Conclusion}

In this paper, a novel PV-wind hybrid power conversion system is proposed first. Then, energy-balanced criterion is applied to the derivation of the voltage gain of the power conversion system. This criterion simplifies the mathematical derivation of the PV-wind hybrid system. For verification, a prototype of the proposed PV-wind hybrid-power conversion 


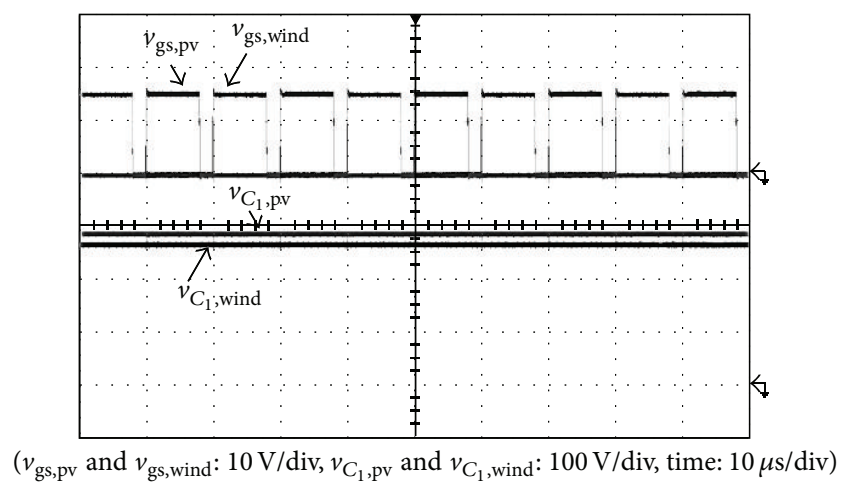

Figure 6: Waveforms of control signals $\left(v_{\mathrm{gs}, \mathrm{pv}}\right.$ and $\left.v_{\mathrm{gs} \text {,wind }}\right)$ and capacitor voltage $\left(v_{C_{1} \text {, wind }}\right.$ and $\left.v_{C_{1}, \mathrm{pv}}\right)$.

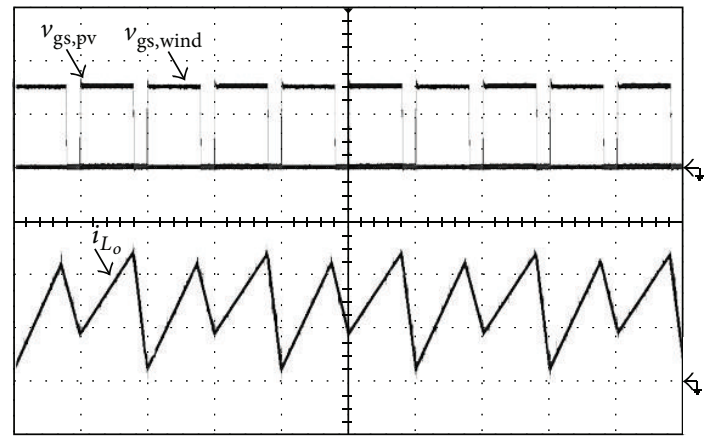

$\left(v_{\mathrm{gs}, \mathrm{pv}}\right.$ and $v_{\mathrm{gs}, \text { wind }}: 10 \mathrm{~V} / \mathrm{div}, i_{L_{o}}: 2 \mathrm{~A} / \mathrm{div}$, time: $\left.10 \mu \mathrm{s} / \mathrm{div}\right)$

FIGURE 7: Waveforms of control signals ( $v_{\mathrm{gs}, \mathrm{pv}}$ and $\left.v_{\mathrm{gs}, \text { wind }}\right)$ and output inductor current $\left(i_{L_{o}}\right)$.

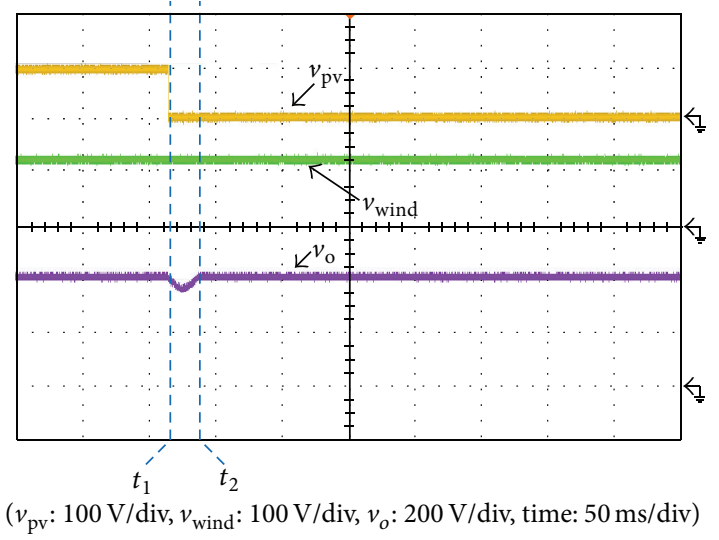

FIGURE 8: The measured output voltage waveform $\left(v_{o}\right)$ to demonstrate the correctness of the mathematically derived result.

system is set up and measured. The practical measurements have proven the correctness of the mathematical derivation. This analysis procedure can be applied to other hybrid greenenergy conversion systems to resolve complicated mathematical problems related to the solution of voltage gain.

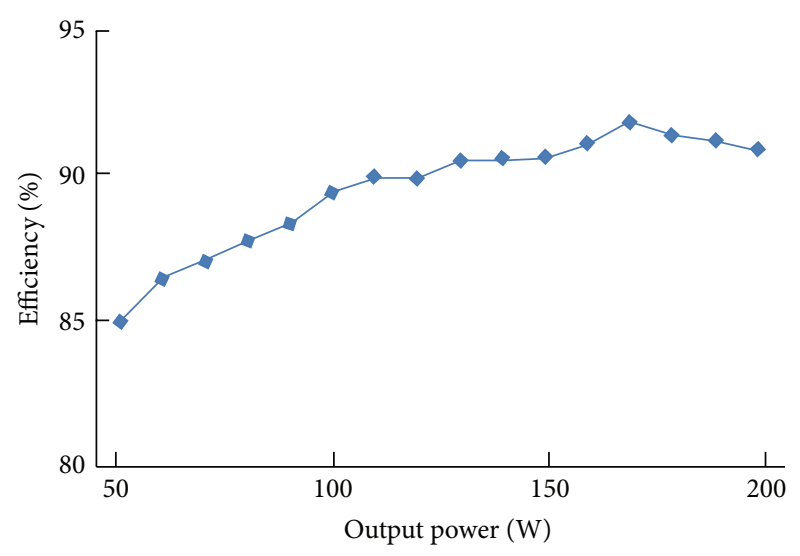

FIgURE 9: The measured efficiency over the range from light load to full load.

\section{Conflict of Interests}

The authors declare that there is no conflict of interests regarding the publication of this paper.

\section{Acknowledgment}

The authors gratefully acknowledge financial support from the Ministry of Science and Technology, Taiwan, under Contract no. MOST 103-3113-E-006-011.

\section{References}

[1] C.-L. Shen and J.-C. Su, "Grid-connection half-bridge PV inverter system for power flow controlling and active power filtering," International Journal of Photoenergy, vol. 2012, Article ID 760791, 8 pages, 2012.

[2] N. Onat, "Recent developments in maximum power point tracking technologies for photovoltaic systems," International Journal of Photoenergy, vol. 2010, Article ID 245316, 11 pages, 2010.

[3] N. Vázquez, C. M. Sanchez, C. Hernández, E. Vázquez, L. D. C. García, and J. Arau, "A different three-port DC/DC converter for standalone PV system," International Journal of Photoenergy, vol. 2014, Article ID 692934, 13 pages, 2014.

[4] S.-Y. Tseng, C.-C. Chen, and H.-Y. Wang, "Buck-boost/forward hybrid converter for PV energy conversion applications," International Journal of Photoenergy, vol. 2014, Article ID 392394, 14 pages, 2014.

[5] K. I. Hwu, W. C. Tu, and C. R. Wang, "Photovoltaic energy conversion system constructed by high step-up converter with hybrid maximum power point tracking," International Journal of Photoenergy, vol. 2013, Article ID 275210, 9 pages, 2013.

[6] S.-Y. Tseng and C.-T. Tsai, "Photovoltaic power system with an interleaving boost converter for battery charger applications," International Journal of Photoenergy, vol. 2012, Article ID 936843, 15 pages, 2012.

[7] S.-K. Changchien, T.-J. Liang, J.-F. Chen, and L.-S. Yang, "Stepup DC-DC converter by coupled inductor and voltage-lift technique," IET Power Electronics, vol. 3, no. 3, pp. 369-378, 2010. 
[8] Z. Zhang, O. C. Thomsen, M. A. E. Andersen, and H. R. Nielsen, "A novel dual-input isolated current-fed DC-DC converter for renewable energy system," in Proceedings of the 26th Annual IEEE Applied Power Electronics Conference and Exposition (APEC '11), pp. 1494-1501, March 2011.

[9] X. Y. Xu, A. M. Khambadkone, and R. Oruganti, "An asymmetrical half bridge flyback converter with zero-voltage and zerocurrent switching," in Proceedings of the 30th Annual Conference of IEEE Industrial Electronics Society (IECON '04), vol. 1, pp. 767-772, November 2004.

[10] S.-K. Changchien, T.-J. Liang, J.-F. Chen, and L.-S. Yang, "Novel high step-up DCDC converter for fuel cell energy conversion system," IEEE Transactions on Industrial Electronics, vol. 57, no. 6, pp. 2007-2017, 2010.

[11] Z. Wang, F. Liu, Y. Mao, and X. Ruan, "Asymmetrical half-bridge double-input DC/DC converters adopting pulsating voltage source cells for low power applications," IEEE Transactions on Power Electronics, vol. 29, no. 9, pp. 4741-4751, 2014.

[12] K.-C. Tseng and C.-C. Huang, "High step-up high-efficiency interleaved converter with voltage multiplier module for renewable energy system," IEEE Transactions on Industrial Electronics, vol. 61, no. 3, pp. 1311-1319, 2014.

[13] F. Nejabatkhah, S. Danyali, S. H. Hosseini, M. Sabahi, and S. M. Niapour, "Modeling and control of a new three-input dc-dc boost converter for hybrid PV/FC/battery power system," IEEE Transactions on Power Electronics, vol. 27, no. 5, pp. 2309-2324, 2012.

[14] C.-L. Shen and T.-C. Liang, "Design and implementation of a high-voltage generator with output voltage control for vehicle ER shock-absorber applications," Mathematical Problems in Engineering, vol. 2013, Article ID 324590, 6 pages, 2013.

[15] C.-L. Shen and S.-H. Yang, "Multi-input converter with MPPT feature for wind-PV power generation system," International Journal of Photoenergy, vol. 2013, Article ID 129254, 13 pages, 2013.

[16] R.-J. Wai, W.-H. Wang, and C.-Y. Lin, "High-performance stand-alone photovoltaic generation system," IEEE Transactions on Industrial Electronics, vol. 55, no. 1, pp. 240-250, 2008. 


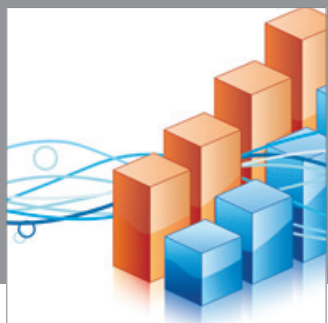

Advances in

Operations Research

mansans

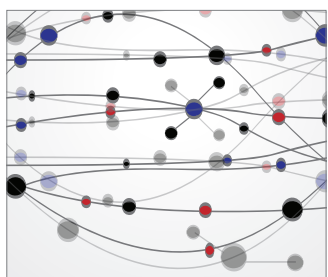

The Scientific World Journal
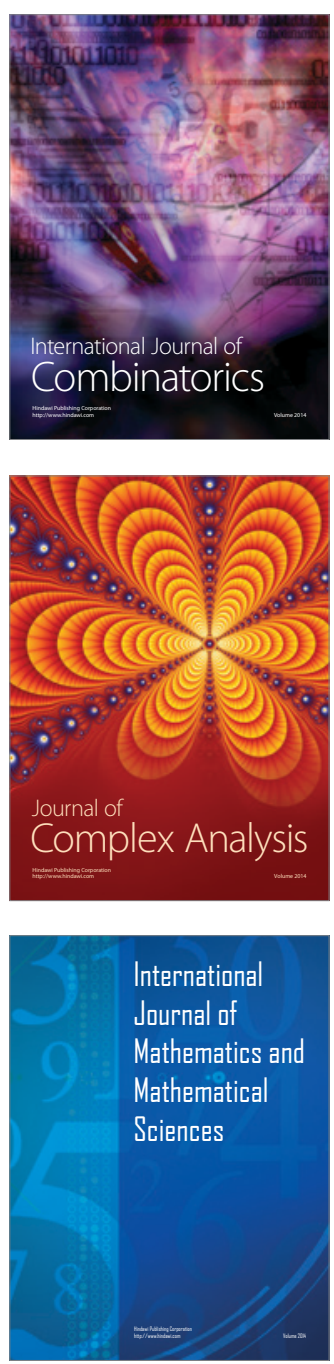
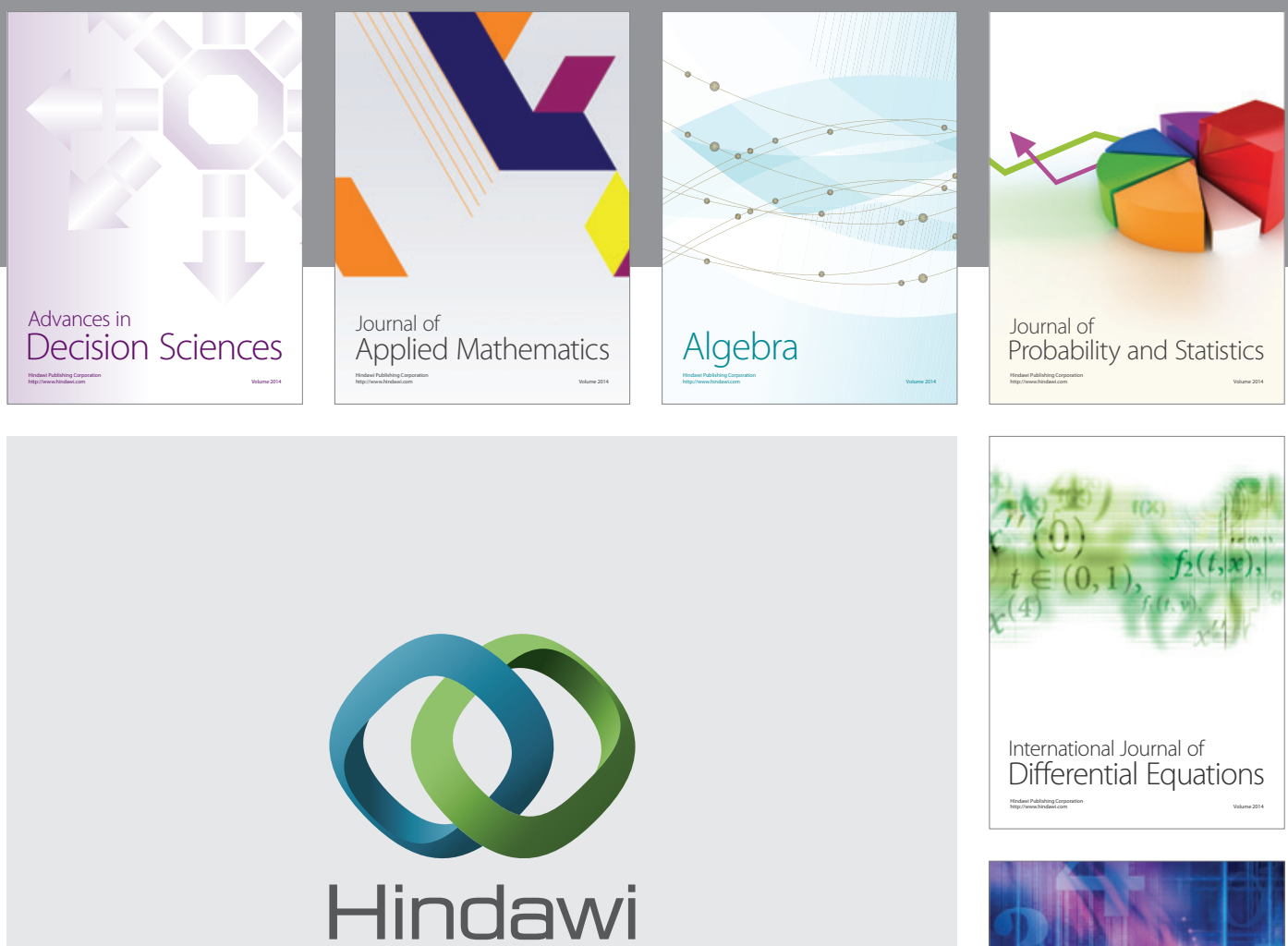

Submit your manuscripts at http://www.hindawi.com
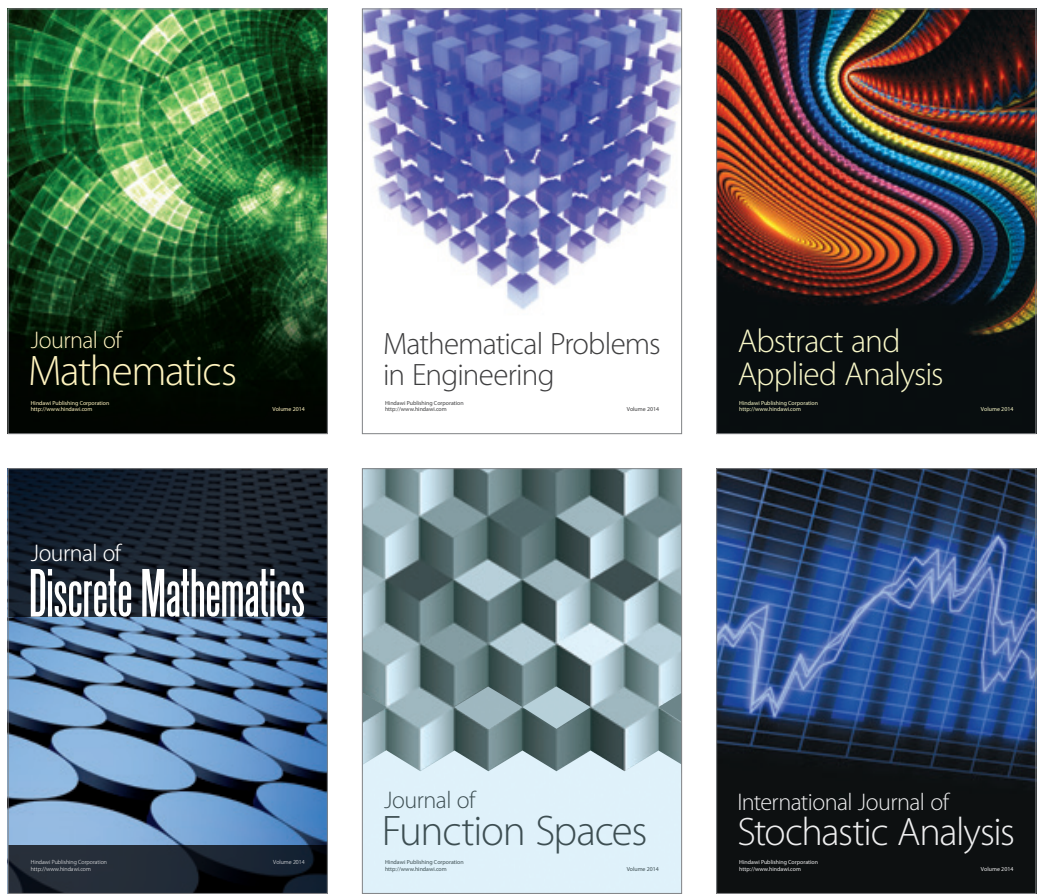

Journal of

Function Spaces

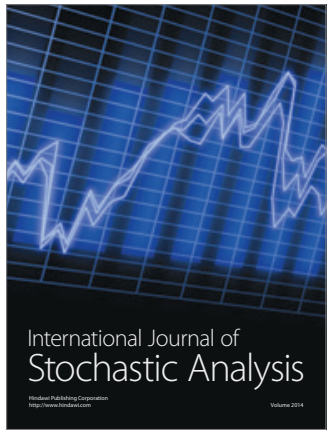

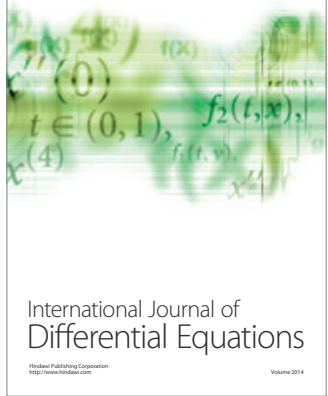
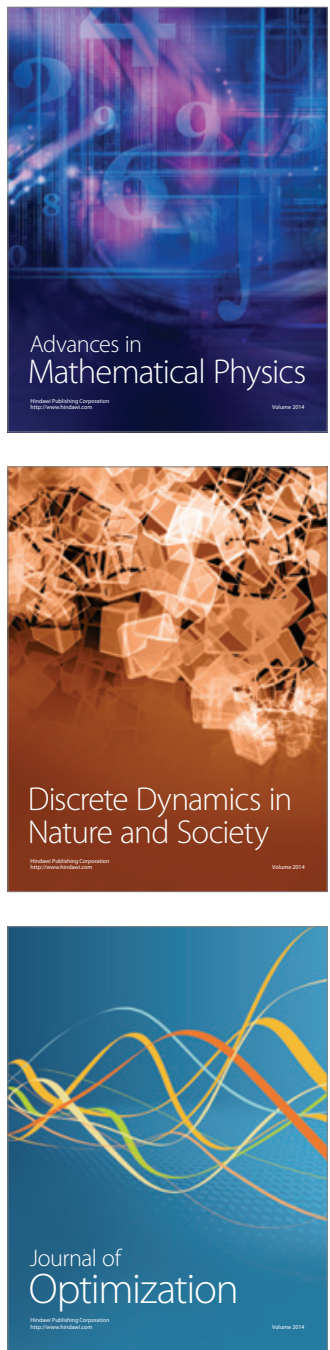